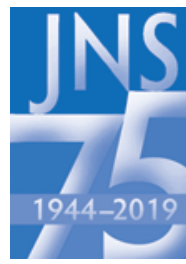

\title{
The Chiari I malformation
}

\author{
JNSPG 75th Anniversary Invited Review Article
}

Samuel G. McClugage III, MD, and W. Jerry Oakes, MD

Department of Neurosurgery, University of Alabama at Birmingham, Alabama

As with many pathologies, the course of our understanding of the Chiari I malformation (CIM) has developed extensively over time. The early descriptions of the Chiari malformations by Hans Chiari in 1891 opened the door for future classification and research on this topic. However, even over a long timeframe, our understanding of the pathophysiology and, more importantly, treatment, remained in its infancy. As recently as the 1970s, CIM was not discussed in popular neurology textbooks. Syringomyelia is listed as a degenerative disorder with no satisfactory treatment. Radiation therapy was considered an option in treatment, and surgery was thought to play no role. During the last 40 years, equivalent to the duration of a neurosurgical career, our understanding of the pathophysiology and natural history of CIM, coupled with modern MRI, has improved the treatment paradigm for this patient population. More importantly, it has given us evidence confirming that CIM is a disorder responsive to surgical intervention, giving patients once thought to be destined for lifelong disability a comparatively normal life after treatment. The purpose of this article is to offer a review of CIM and its important associated entities. The authors will discuss the evolution in understanding of the Chiari malformation and, importantly, distinguish between symptomatic CIM and asymptomatic tonsillar ectopia, based on imaging and presenting symptomatology. They will discuss techniques for surgical intervention, expected outcomes, and complications after surgery. Proper patient selection for surgery based on appropriate symptomatology is tantamount to achieving good surgical outcomes in this population, separating those who can be helped by surgery from those who are unlikely to improve. While our knowledge of the Chiari malformations continues to improve through the efforts of clinical and basic science researchers, surgeons, and patients, our current understanding of these entities represents a monumental improvement in patient care over a relatively short time period.

https://thejns.org/doi/abs/10.3171/2019.5.PEDS18382

KEYWORDS Chiari I malformation; tonsillar ectopia; definition; diagnosis; treatment

$\mathrm{H}$ ERNIATION of cerebellar tissue through the foramen magnum causing neurological symptoms has been known for more than 120 years. We group these conditions under the term Chiari malformations to pay tribute to the original description of an autopsy series of patients that was carefully examined and reported..$^{10,11}$ The field remained relatively quiet clinically until the 1970s, with the introduction of insights from Gardner ${ }^{21,22}$ and Williams. ${ }^{67,68}$ Both believed the problem centered on the lack of free movement of CSF across of the craniocervical junction or out of the fourth ventricle. The lack of dissipation of the CSF pulsation into the spinal subarachnoid space was thought somehow to cause syrinx formation. ${ }^{67,68}$ However, it was not until the advent of MRI that the diagnosis began to take shape. Even with new imaging modalities, we struggled at the time to establish what constituted significant cerebellar descent and what type of symptoms could be relieved by surgical intervention. Today the presentation of patients with symptomatic cerebellar tonsillar herniation is recognized much more commonly, and we need to guard against attributing more symptoms to the MRI findings than is justified.

In this article, we will review our understanding of the Chiari I malformation (CIM), how it presents clinically, what surgical options are available, and how likely symptoms may resolve. We will limit the bulk of the discussion to the CIM and not discuss the cerebellar vermis herniation seen in myelomeningocele patients with Chiari II malformation (CIIM). We must also mention that any discussion of CIM is tightly connected to the development of syringomyelia, which we will not discuss exhaustively but will mention relevant issues when appropriate.

ABBREVIATIONS CIM = Chiari I malformation; CIIM = Chiari II malformation; ICP = intracranial pressure; PICA = posterior inferior cerebellar artery.

SUBMITTED May 12, 2019. ACCEPTED May 14, 2019

INCLUDE WHEN CITING DOI: 10.3171/2019.5.PEDS18382. 


\section{Background and Historical Context}

Much has been written about the history of CIM and the development in understanding through the years, regarding the nature of this condition. ${ }^{35,44,45,52}$ As recently as the 1970s, standard neurology texts did not mention CIM and grouped syringomyelia in the degenerative section. ${ }^{41}$ Surgery was thought to have no value at the time and radiation therapy is instead noted as a treatment option. ${ }^{41} \mathrm{We}$ mention this not to condemn a well-recognized text but to underscore how far our understanding has progressed within a few short decades. These advances have allowed for the appropriate treatment of a population of patients once thought to be resigned to lifelong disability.

Early descriptions of cerebellar tonsillar herniation and syringomyelia are found at least as far back as the 19th century. ${ }^{32,44}$ Hans Chiari deserves the bulk of the credit for the first series of autopsied patients and a classification of the findings still used today. ${ }^{10,11}$

Much has been written and conjectured about the cause of the cerebellar displacement in CIM, but to date, no single definitive cause has been identified. Clearly, raised intracranial pressure (ICP) can force the cerebellar tonsils through the foramen magnum, which will result in caudal displacement of the tonsils if it develops beyond the second trimester of in utero growth. ${ }^{64}$ Prior to that embryonic time point, the tonsils have not formed, and the cerebellar vermis will instead be caudally displaced. ${ }^{64}$ This explains the different anatomical herniation seen between CIM and CIIM, with CIIM patients having their cerebellar vermis and brainstem displaced caudally, instead of the cerebellar tonsils seen in CIM. This process can be successfully mitigated in patients with myelomeningocele by performing in utero closure of the neural tube defect. ${ }^{1}$ The position of the choroid plexus is also notable in CIIM. In these patients, migration of choroid plexus into the roof of the fourth ventricle is arrested, so it is maintained in its embryonic extraventricular position (Fig. 1). ${ }^{64}$ In those rare situations where exploration of a CIIM is indicated, the extraventricular choroid plexus can guide the surgeon to locating an opening into the fourth ventricle and reestablishing CSF egress out of the ventricular system. In the modern era, it is uncommon for CIIM patients to develop medullary compression symptoms or a symptomatic syrinx that requires decompression of the craniocervical junction. ${ }^{29}$ We now understand that the hindbrain dysfunction seen in myelomeningocele patients with symptoms of inspiratory wheezing or pulmonary aspiration can be attributed to raised ICP or intrinsic medullary dysfunction, and generally not direct compression. ${ }^{29}$ In these patients, if symptoms persist or recur after definitive treatment of hydrocephalus, consideration must be made to evaluate the patient for adequacy of treatment for raised ICP. Patients who remain symptomatic despite adequate treatment of hydrocephalus may be considered for tracheostomy and/or gastrostomy placement, and many will eventually recover significant medullary function with time. ${ }^{29,61}$ The evolution in understanding and changes in approach to this life-threatening problem have saved countless infants and children with CIIM the burden of an unnecessary hindbrain decompression.

Several causes of acquired cerebellar tonsillar herniation have also been documented. Low intraspinal pressure

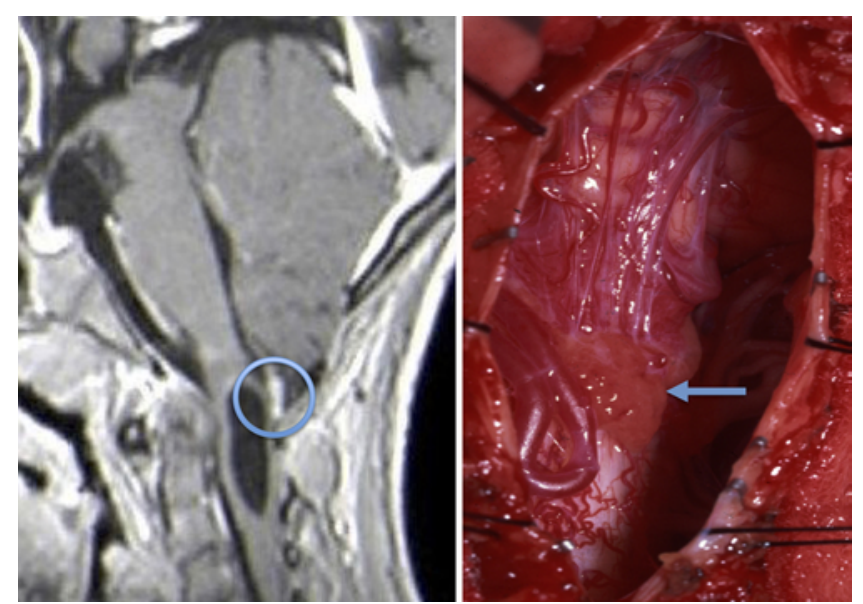

FIG. 1. The choroid plexus in patients with CIIM is maintained in its embryonic extraventricular position, due to failure of migration to the roof of the fourth ventricle. Left: Sagittal contrast-enhanced MR image showing enhancing choroid plexus (blue circle) in the extraventricular position. Right: Intraoperative intradural exposure of a CIIM with visualization of the extraventricular choroid plexus (blue arrow) and adjacent caudal loop of the PICA. Figure is available in color online only.

relative to a normal ICP can also produce an acquired displacement of the tonsils, causing caudal movement of the cerebellum when there is a pressure gradient across the foramen magnum. ${ }^{12}$ Some attention has rightly been given to a primary mesodermal disturbance in development of the bony compartment of the posterior fossa, resulting in a volume inadequate for housing the growing cerebellum and brainstem. ${ }^{36}$ This mechanism can help explain some of the severe forms of CIM and syrinx seen in conjunction with craniosynostosis and other forms of restricted skull growth. Cerebellar tonsillar herniation can also be seen in processes that inhibit the free movement of CSF out of the fourth ventricle and into the spinal subarachnoid space due to scarring, such as tuberculous meningitis. ${ }^{2}$ Arachnoid veils that form over the foramen of Magendie (Fig. 2) and hemorrhage associated with subarachnoid scarring that occurs near the foramen can also cause CIM and/or syrinx formation. Mass lesions of the foramen magnum or posterior fossa may also cause tonsillar herniation or syrinx formation. Clearly, many different etiologies can cause cerebellar tonsillar descent with or without syrinx formation, and it is reasonable to consider these as separate entities from CIM, rather than focusing on their final common consequence of caudal tonsillar displacement.

\section{Definition of CIM}

The definition of CIM is more complicated than it would initially seem. As with many other pathological entities, the line that separates early pathological change from normal anatomical variant can be somewhat blurred. ${ }^{20}$ The problem arises from the distinction between "symptomatic" CIM, "asymptomatic" CIM, and "tonsillar ectopia" and how those entities are defined. Is the clinical diagnosis and definition of CIM purely radiological or does it depend on the co-occurrence of proper radiological and clinical findings? CIM, as a solely radiological finding 

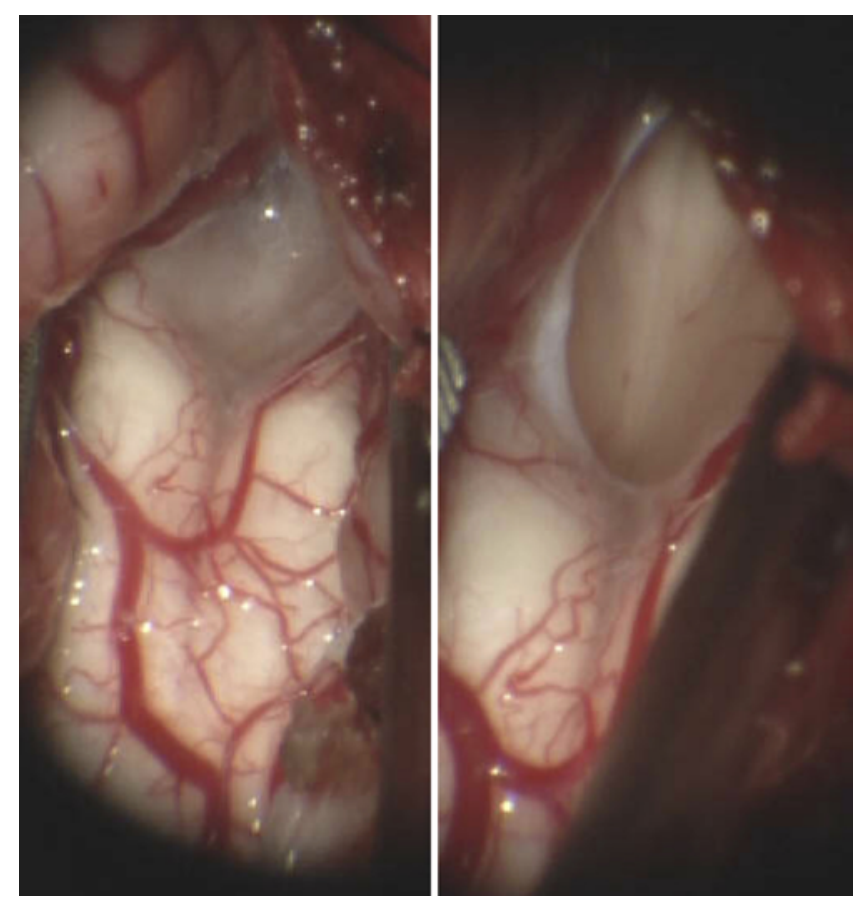

FIG. 2. Intraoperative intradural exposure of the craniocervical junction dorsally, showing an arachnoid veil causing fourth ventricular outlet obstruction, after initial exposure (left) and after opening of the veil to relieve the obstruction (right). Figure is available in color online only.

on MRI, is defined as herniation of the cerebellar tonsils below the foramen magnum of $>3 \mathrm{~mm}$ in children and $>5 \mathrm{~mm}$ in adults.,60 This is found in up to $0.9 \%$ of the general adult population and $0.6 \%$ of the general pediatric population. ${ }^{28,65}$ One can further categorize patients with radiological tonsillar ectopia by anatomical findings at the foramen magnum, namely the presence or absence of "peg-like" or "pointed" tonsils and effacement of CSF spaces. ${ }^{60}$ Lesions with these findings are more likely to be associated with symptomatic patients. ${ }^{7}$

As our understanding of CIM improved, variations in the definition began to become more obvious. In the standard definition of CIM, the brainstem is not caudally displaced. This is in contrast to CIIM, in which the cerebellar vermis and brainstem are both caudally displaced. The hybrid condition, with displacement of the cerebellar tonsils and brainstem without an associated myelomeningocele, is referred to as a Chiari 1.5 malformation. ${ }^{59} \mathrm{~Pa}-$ tients with these lesions appear to have a more concerning natural history than CIM patients, who do not exhibit brainstem descent. ${ }^{59}$ Another small group of patients was recognized with no cerebellar tonsillar descent but had a syrinx that resolved after posterior fossa decompression, intradural exploration, and opening of the fourth ventricular outlet (Fig. 3), what we now refer to as the Chiari 0 malformation. ${ }^{9}$ This group was universally found to have significant scarring or obstruction of the fourth ventricular outlet, which precluded dissipation of the CSF pulse out of the ventricular system. ${ }^{9}$ It should be noted the term Chiari 0 should be restricted to patients with a significant syrinx in the absence of tonsillar herniation.

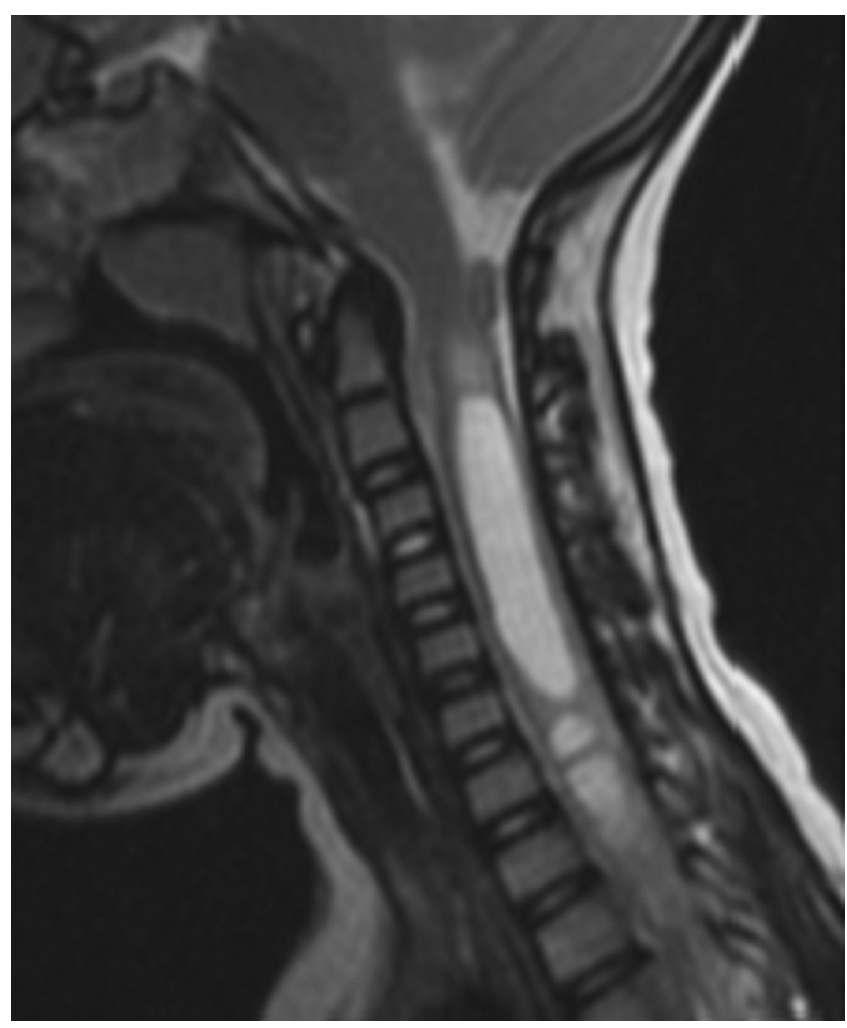

FIG. 3. Sagittal T2-weighted MR image showing a large cervical syrinx without cerebellar tonsillar herniation, consistent with a Chiari 0 malformation.

\section{Symptoms, Clinical Presentation, and Patient Selection in CIM}

The clinical presentation of CIM differs slightly between adult and pediatric patient populations. Pediatric patients are more likely to present with signs of brainstem dysfunction, such as central sleep apnea or feeding difficulties. ${ }^{24}$ This is likely due to the difficulty of assessing headache and localizing pain in infants and younger children, causing them to present later in their clinical course after neurological sequelae have developed. The most common presenting symptom of CIM, in both adult and pediatric patients, is pain or headache within the occipital and cervical region. ${ }^{57}$ Classically, this is produced by Valsalva activities, such as coughing, sneezing, or laughing. ${ }^{57}$ Headaches can obviously be a difficult symptom to elucidate in a nonverbal population, such as infants and young children. Instead, pain symptoms can manifest as excessive crying, irritability, failure to thrive, and, in extreme situations, opisthotonos. ${ }^{34,60}$

Aside from the aforementioned exceptions, symptoms of CIM generally correlate between adult and pediatric patient populations. Symptoms can typically be assigned to one of three categories: 1) symptoms related to CSF obstruction, 2) symptoms related to brainstem or cerebellar compression/dysfunction (including cranial nerves), and 3) symptoms related to spinal cord dysfunction/syringomyelia (Table 1).

Valsalva- or strain-induced headaches are the sequelae 
TABLE 1. Symptoms of CIM

\begin{tabular}{lll}
\hline \multicolumn{1}{c}{ CSF Obstruction } & $\begin{array}{c}\text { Compression of Brainstem, Cerebellum, } \\
\text { or Cranial Nerves }\end{array}$ & Spinal Cord Dysfunction (syringomyelia) \\
\hline $\begin{array}{l}\text { Valsalva- or strain-induced occipital/upper } \\
\text { cervical pain/headache }\end{array}$ & $\begin{array}{c}\text { Swallowing difficulty/choking/aspiration, } \\
\text { dysphagia }\end{array}$ & Upper motor neuron signs \\
\hline Hydrocephalus & Hoarseness/dysarthria & Lower motor neuron signs \\
\hline & Absent gag reflex & Pain and temperature sensory loss \\
\hline Central sleep apnea/snoring & Spasticity \\
\hline Downbeat nystagmus & Scoliosis (primarily thoracic levoscoliosis) \\
\hline Truncal ataxia & Motor weakness \\
\hline Tinnitus & \\
\hline Vertigo/dizziness & \\
\hline Autonomic symptoms (syncope, drop & \\
\hline \multicolumn{3}{c}{ attacks, sinus bradycardia) } \\
\hline & Trigeminal/glossopharyngeal neuralgia & \\
\hline & Trigeminal sensory loss & \\
\hline & Tongue weakness/deviation & \\
\hline
\end{tabular}

of CSF obstruction at the foramen magnum commonly associated with CIM. They can be caused by either tonsillar descent into the foramen with obstruction or arachnoid occlusions of the CSF pathways, resulting in transient increases in ICP. Headaches of this nature are localized to the occipital and upper cervical region and are induced by Valsalva-producing activities. They are typically brief, lasting seconds or a few minutes. It is important to note the specificity of headache type associated with CIM. Frequently, patients also complain of chronic headaches, migrainous symptoms, or non-Valsalva maneuver-induced headaches, but these are not typically attributable to CIM pathophysiology and should not be used as a justification for surgical intervention. ${ }^{39}$

Symptoms related to brainstem, cerebellar, or cranial nerve dysfunction can include a plethora of findings related to these structures. Most commonly, the glossopharyngeal and vagus nerves are affected, resulting in an absent gag reflex, hoarseness, and swallowing difficulty. ${ }^{15}$ Less commonly, the trigeminal, facial, abducens, and hypoglossal nerves are affected..$^{15}$ Nystagmus, classically downbeat nystagmus, is associated with dysfunction at the cervicomedullary junction but is not specific to CIM. ${ }^{13,14}$ Balance problems tend to manifest as truncal ataxia and difficulties with gait. ${ }^{47}$ Tinnitus, dizziness, and vertigo have also been reported ${ }^{43}$ Rarely, direct brainstem compression may cause autonomic symptoms, such as syncopal episodes, ${ }^{66}$ drop attacks, ${ }^{15}$ and sinus bradycardia. ${ }^{51}$ Central sleep apnea is the most common manifestation of brainstem/ medullary compression in CIM, seen in roughly $13 \%$ of pediatric patients at presentation and more common in children younger than 6 years of age. ${ }^{46,54}$ Sleep studies can be useful for elucidating evidence of central sleep apnea if patients present with CIM and concern for snoring.

Spinal cord dysfunction most commonly manifests due to syringomyelia associated with CIM. Upper and lower motor neuron signs can both be seen and are frequently present in the same patient. Sensory dysfunction typically affects pain and temperature, while light touch and proprioception remain unaffected. ${ }^{50}$ Scoliosis can also be a manifestation of syringomyelia in the pediatric population. ${ }^{57}$ Levoscoliosis and single curve is more concerning for CIM and syringomyelia, as opposed to dextroscoliosis, which is most commonly associated with idiopathic scoliosis. $^{27}$

In making the decision to treat a patient with CIM, an understanding of the natural history is important. The natural history of asymptomatic or minimally symptomatic CIM is likely benign, with $>93 \%$ of patients remaining clinically stable or improving after serial imaging with several years of follow-up. ${ }^{33,55}$ Thus, in this patient population, follow-up with serial imaging is a reasonable approach. This includes patients with non-Valsalva-induced headaches or atypical headaches, who should not be considered for surgery without more obvious referable symptoms. Indications for surgical intervention should include only those in patients with obvious symptoms attributable to either the CIM or a spinal syrinx. These populations include the following: 1) patients with classic Valsalvainduced headaches, 2) patients with an associated syrinx, and 3) patients with neurological sequelae associated with pathology at the foramen magnum, cervicomedullary junction, or lower cranial nerve dysfunction. These indications are generally accepted for surgical intervention in pediatric and adult patient populations with CIM.

\section{Imaging and Diagnostic Studies in CIM}

The imaging modality of choice is MRI for patients with cerebellar tonsillar ectopia and concern for CIM and syringomyelia. Patients with evidence or concern for tonsillar ectopia should undergo spinal and brain MRI to assess tonsillar and brainstem position and the presence of a syrinx. Other associated imaging findings suggestive of 


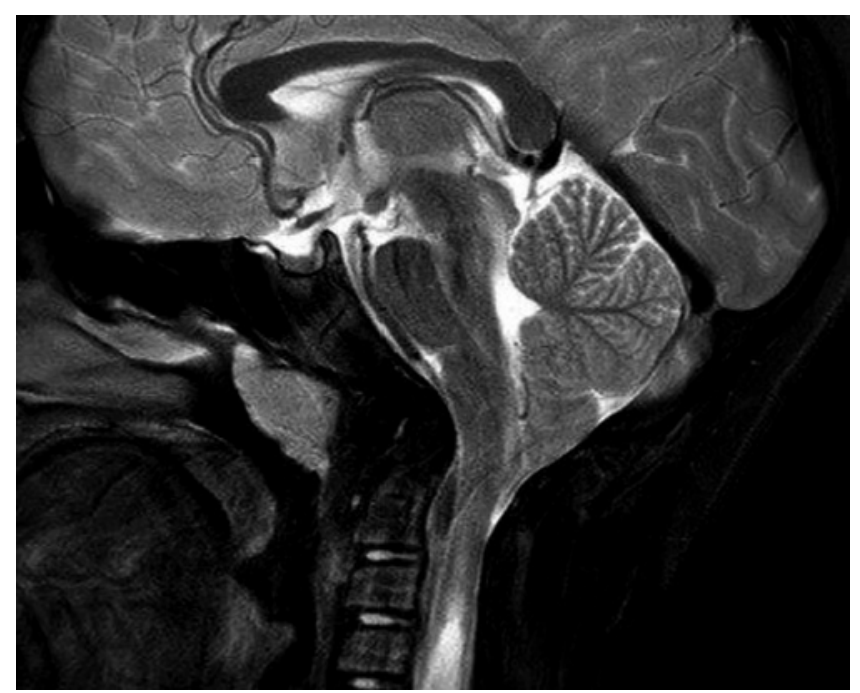

FIG. 4. Midline sagittal T2-weighted MR image of the craniocervical junction showing the peg-like appearance of tonsils and effacement of basilar CSF cisterns. This patient also exhibits caudal descent of the brainstem, consistent with a Chiari 1.5 malformation.

symptomatic lesions include cervicomedullary kinking, crowding of the foramen magnum with effacement of CSF spaces, and tonsillar pegging (Fig. 4). Cranial imaging must also be preformed to exclude hydrocephalus and mass lesions, as both can cause secondary tonsillar movement.

Barkovich et al. compared a large population of "normal" patients to a symptomatic CIM population and concluded that tonsillar ectopia of $2 \mathrm{~mm}$ or less was of minimal significance. ${ }^{7}$ The authors accepted a definition of CIM as greater than $5 \mathrm{~mm}$ of caudal displacement of the tonsils. Mikulis et al. published an interesting study in 1992, looking at age-related changes to normal tonsillar position. ${ }^{42}$ They noted that tonsillar ascent occurred with increasing age, with a bimodal distribution of ascent being most rapid both early in childhood/early adulthood and late after the 7 th decade. ${ }^{42}$ They documented the amount of descent outside two standard deviations from normal for each age group, noting $6 \mathrm{~mm}$ at 10 years of age, $5 \mathrm{~mm}$ between 10 and 30 years, $4 \mathrm{~mm}$ between 30 and 79 years, and $3 \mathrm{~mm}$ thereafter to be abnormal. ${ }^{42}$ The lesson learned is that no single measurement is sufficient to diagnose CIM without supportive clinical and radiological findings, and children can have greater tonsillar ectopia without symptoms than adults, given the normal age-related ascent associated with the cerebellar tonsils. ${ }^{16}$ Furthermore, sagittal MRI has been shown to overestimate the degree of tonsillar herniation, leading to a risk of misdiagnosis and unnecessary consults and referrals. ${ }^{63}$

Other imaging modalities, such as cardiac-gated phasecontrast MRI or cine MRI, can be useful for evaluating CIM patients, assessing CSF flow and tonsillar dynamics at the foramen magnum. Phase-contrast MRI differs from normal MRI, in that it studies dynamic processes, such as blood and CSF flow, as opposed to the static anatomical properties revealed by standard MRI modalities. ${ }^{8}$ The value of these studies in determining a need for surgical intervention remains speculative. There is a correlation between postoperative symptom improvement and improved CSF flow on cine MRI at the foramen magnum., ${ }^{5,40}$ However, phase-contrast MRI should be used cautiously in evaluating CIM patients, as the interrater reliability of these studies can be poor, especially for patients with only moderate CSF flow dysfunction. ${ }^{26}$

More recently, diffusion tensor imaging has been used to assess white matter tract dysfunction in the medulla of CIM patients. ${ }^{18}$ There was greater fractional anisotropy in patients with CIM than in those without, suggesting some component of white matter tract dysfunction, and this showed improvement after surgical decompression. ${ }^{31}$

\section{Surgical Treatment of CIM}

Patients are positioned prone with the head fixated. Even for young infants, it is safe to apply pin fixation judiciously to prevent intraoperative movement of the head. The head of the bed is elevated $20^{\circ}-30^{\circ}$ to decrease venous pressure, and the neck is flexed. If there is concern about medullary compression with flexion, this can be tested preoperatively to determine the extent of movement comfortable for the patient. The incision extends from a fingerbreadth below the external occipital protuberance to the spinous process of $\mathrm{C} 2$. Every effort is made to preserve the dorsal arch of $\mathrm{C} 2$ and its muscular attachments, which mitigates the risk of a postoperative swan neck deformity. The avascular midline plane is separated with monopolar cautery, and the posterior arch of $\mathrm{C} 1$ and the dorsal aspect of the foramen magnum are exposed. The exposure should focus only on midline structures; a more extensive lateral exposure is unnecessary and exposes the patient to the unnecessary risk of a vertebral artery injury. ${ }^{62}$ Bone removal begins at the foramen magnum and should extend 22-25 $\mathrm{mm}$ wide and $20-25 \mathrm{~mm}$ in height. The dorsal arch of $\mathrm{C1}$ is removed, taking care not to compromise the space under the arch with a footplate or other surgical instrument. There is no need for a more extensive bony removal, since the pathology is confined to the foramen magnum and the area under the arch of $\mathrm{Cl}$-hence, bony decompression should focus on these areas alone. Of note, patients with achondroplasia may need additional removal of the medial occipital condyle when the horizontal dimension of the foramen magnum is severely restrictive. ${ }^{6}$

When the bony decompression is complete, a decision is made as to the advisability of a dural opening. In the literature, much energy and thought have gone into determining the utility of this decision. ${ }^{60}$ The surgeon must contrast the risk of a significant complication associated with dural opening with the chance of missing pathology at the outlet of the fourth ventricle, which would remain unrelieved by bony decompression alone. In our experience, an arachnoid veil at the fourth ventricular outlet was present in $12 \%$ of patients with syringomyelia. ${ }^{57}$ Because of this, our own practice has been to open the dura in almost every case, as our experience with dural opening has been relatively benign.

If dural opening is undertaken, the dura under $\mathrm{C} 1$ is opened first since it is anatomically a single layer. ${ }^{49} \mathrm{In}$ small infants, the dural layers at the foramen magnum can be separated by a venous lake, which can bleed exces- 


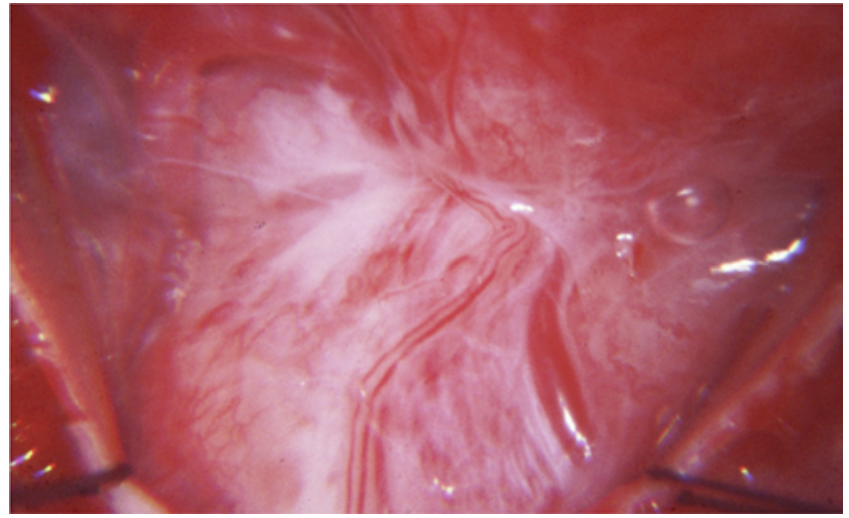

FIG. 5. Intraoperative intradural exposure of the dorsal craniocervical junction in a patient not previously operated on, demonstrating extensive scarring over the cerebellar tonsils and obscuring the fourth ventricular outlet and course of the PICA. Figure is available in color online only.

sively if both layers are not controlled upon opening. ${ }^{49}$ The dura is opened in a Y-shaped fashion to allow for sufficient decompression and inspection of the outlet of the fourth ventricle for an arachnoid veil or scarring (Fig. 5). If a veil or scarring is present, it should be lysed and opened until appropriate CSF egress is noted. Significant care is needed to avoid contamination of the subarachnoid space with blood and to avoid injury to the pial surface of the cerebellar tonsils, both of which can cause postoperative scarring and is counterproductive to the goal of the procedure. Resection or bipolar cautery of the cerebellar tonsils may be necessary to adequately open the fourth ventricular outlet. Care must be taken to perform the tonsillar resection with a subpial technique. We know of no recognized neurological consequences of tonsillar excision, although we doubt this tissue is present without a purpose; this simply underscores our limited ability to examine cerebellar function in full. After adequate decompression and examination for intradural adhesions, a dural patch is harvested through a skip incision from the occipital pericranium and sewn in place.

There are many variations of this basic approach and much current attention is directed to clarifying the risks and benefits of the steps involved. In the end and with experience, this procedure can be performed safely with minimal risk of neurological injury or other serious complication. ${ }^{57}$

\section{Complications of Surgical Decompression in CIM}

As with any surgical procedure, the best approach to dealing with complications is avoidance, and Chiari surgery is no different. Normalizing ICP prior to dural opening avoids many postoperative problems, including pseudomeningocele and CSF leakage from the wound. Even with meticulous dural closure, elevated ICP will find a way through your suturing and become manifest. Interestingly, in the small group of patients receiving a ventriculoperitoneal shunt prior to Chiari decompression, shunt revision has been strikingly uncommon. ${ }^{53}$ Endoscopic third

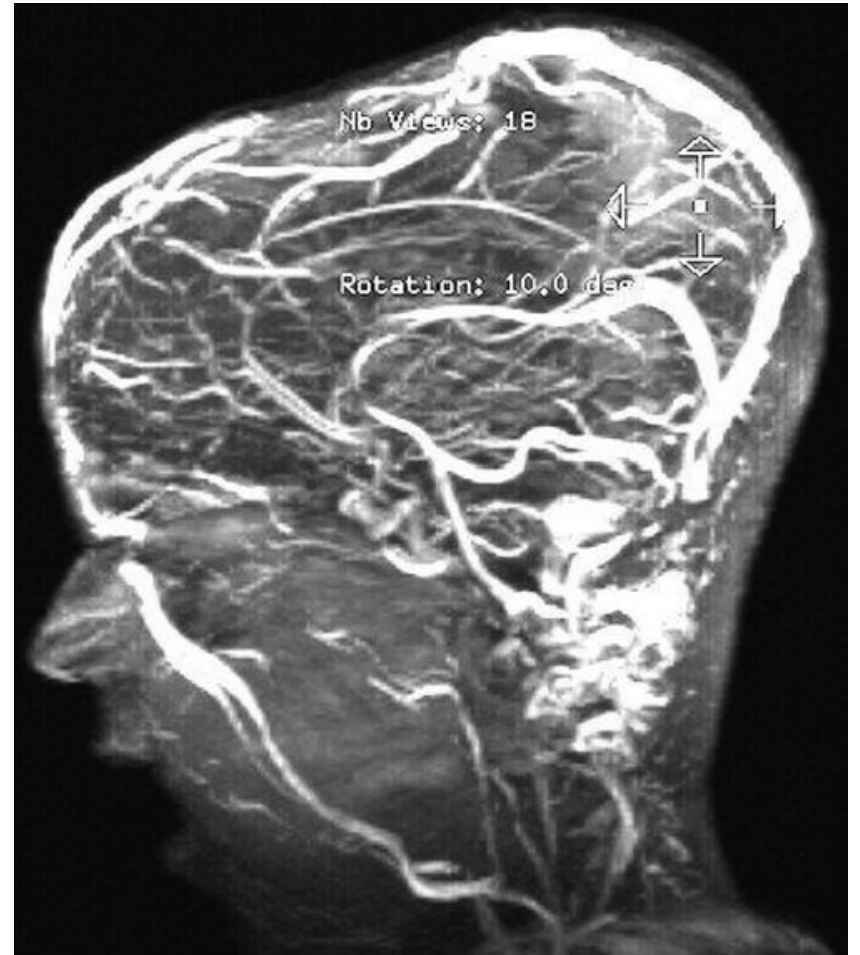

FIG. 6. Midsagittal MR venogram of a patient with Pfeiffer syndrome, demonstrating transosseous venous return through the occipital skull. As a result of bony stenosis of the jugular foramen bilaterally in patients with restricted skull growth, primary venous outflow is redirected through a transosseous route. Surgical decompression in these patients can interrupt venous outflow, resulting in serious venous infarction and death.

ventriculostomy has been proposed as an alternative to ventriculoperitoneal shunt placement, but we have very limited experience with this approach. ${ }^{25,38,69}$ Why there has been such a low shunt revision rate after the Chiari decompression is a matter for speculation.

A small subset of patients with restricted skull growth (e.g., Pfeiffer or Crouzan syndrome) and stenosis of the jugular foramen will convert their normal intracranial venous drainage pattern to a transosseous pattern via emissary veins..$^{19}$ This can be assessed preoperatively with MRI or CT venography and, if severe, may preclude standard posterior fossa approaches (Fig. 6). Suboccipital decompression in these patients will not only result in significant operative hemorrhage but may disrupt the transosseous venous outflow, resulting in significant venous infarction.

Vascular injury to the vertebral artery is avoided by focusing solely on a midline exposure. Wide lateral exposure of $\mathrm{C} 1$ or the occiput is unnecessary, given the midline pathology found in CIM. The course of the vertebral artery is somewhat variable and may track medially in some patients, especially those with major bony or congenital anomalies. ${ }^{62}$ The posterior inferior cerebellar artery (PICA) is at risk during intradural exploration, but careful sharp dissection and knowledge of its course with appropriate protection will minimize the risk of injury. It should be noted that delayed aneurysm formation can occur if the PICA is injured intraoperatively (Fig. 7). As previously discussed, dural opening in the young infant can 


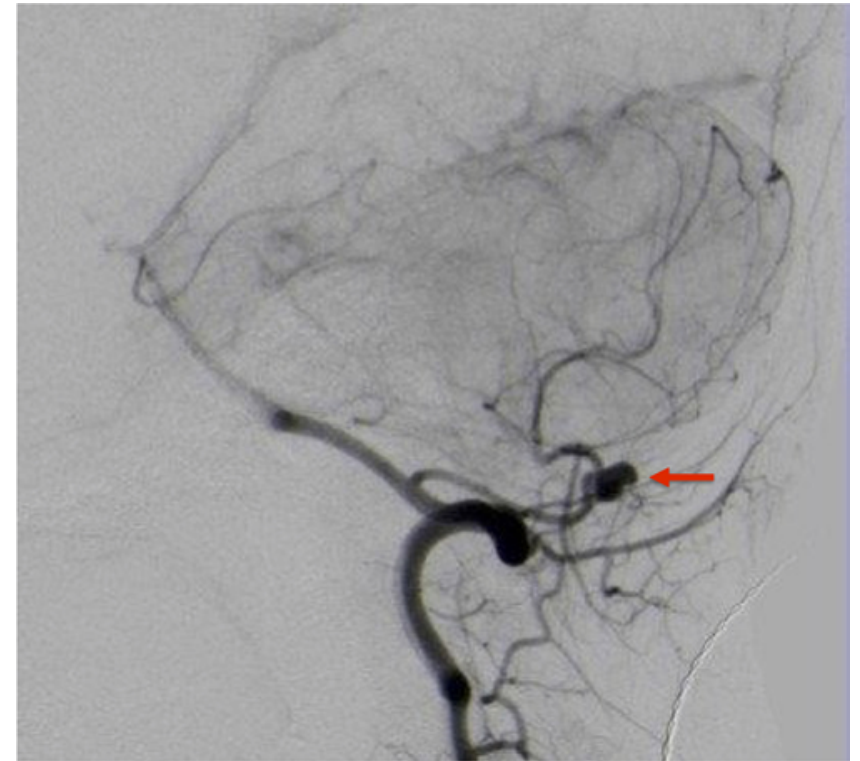

FIG. 7. Delayed presentation of an iatrogenic PICA aneurysm (red arrow), as a result of intraoperative injury during CIM decompression. Figure is available in color online only.

be challenging due to the presence of large venous lakes, and control of both dural leaves is paramount in this process to avoid significant blood loss. ${ }^{49}$

Postoperative development of acute hydrocephalus, caused by accumulation of CSF in the subdural space over the cerebellum, has been reported and is a reason given for avoiding dural opening. ${ }^{17,37}$ In the past several years, we have avoided this complication by clipping the opened arachnoid to the dura during closure. ${ }^{17}$

A small group of patients, almost exclusively young children with significant ventral compression and signs and symptoms of medullary dysfunction, can worsen acutely following a standard decompression. ${ }^{23,30,48}$ This group typically violates the $\mathrm{Pb}-\mathrm{C} 2$ line, a line drawn from the posterior inferior border of $\mathrm{C} 2$ to the basion, by $>9$ $\mathrm{mm} \cdot{ }^{23}$ Flexion-extension radiographs or MR images may help predict this and preoperative improvement with cervical traction can help determine if occipitocervical fusion is justified in combination with a standard decompression. Soft-tissue pannus behind the dens is indicative of microinstability and may not be readily apparent on flexion-extension imaging. Cervical fusion may also be indicated in these patients. It should be emphasized that this combination is very uncommon.

Recent experience has underscored the need for longterm follow-up, even after successful suboccipital decompression (Fig. 8). Syrinx resolution after decompression can be followed years or decades later by symptomatic syrinx recurrence; hence, long-term clinical surveillance is justified. ${ }^{3,4,57}$ Once burning dysesthesia develops, particularly in adults, it may not improve even with syrinx resolution. ${ }^{56}$

\section{Results of Surgical Decompression in CIM}

In discussing the results of surgical intervention, we will restrict our comments to what we have observed directly rather than a literature review of what is possible. The characteristic headache with all three classic components (occipital or high cervical pain in location, specifically
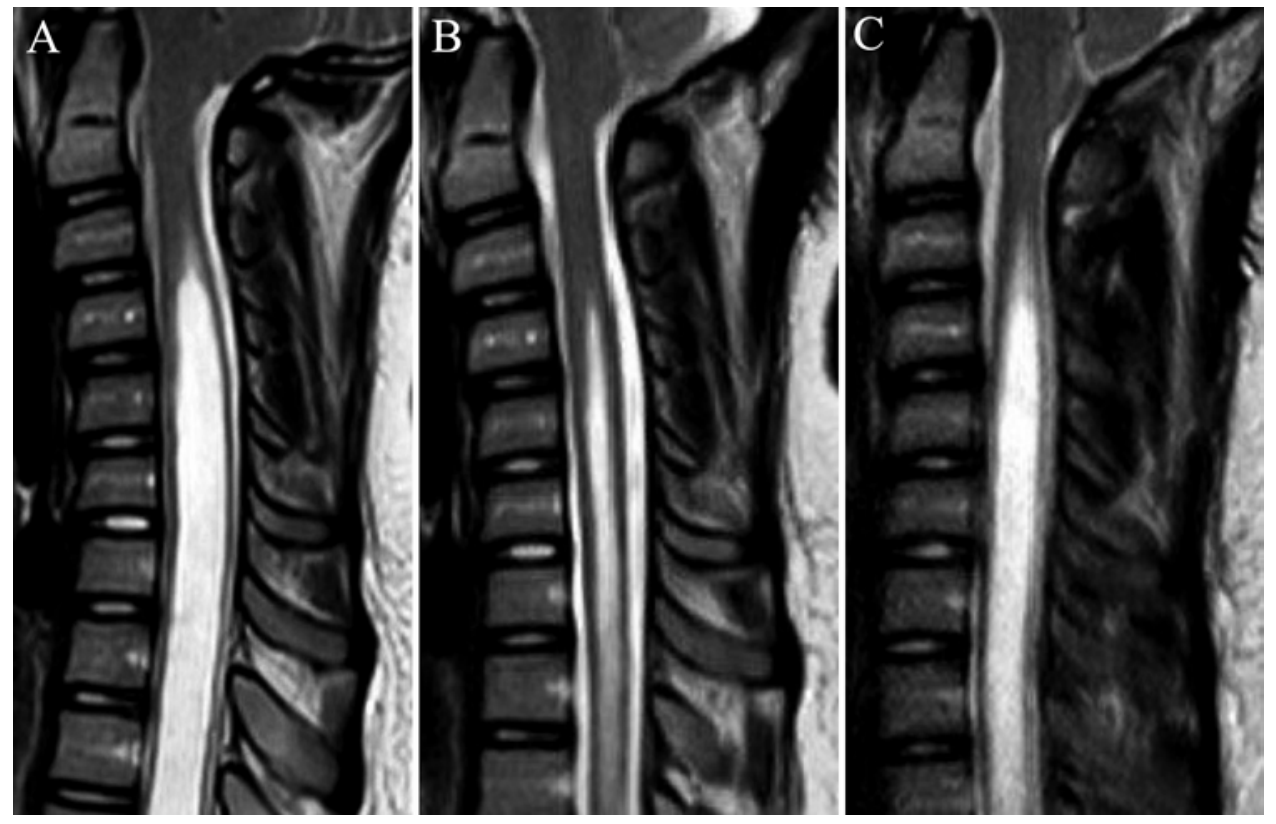

FIG. 8. Follow-up of patients after decompression for CIM is important, given the possibility of recurrence of symptoms and pathology at the craniocervical junction. A: Preoperative midsagittal T2-weighted MR image demonstrating CIM and a syrinx. B: Image obtained at the 6-month follow-up, showing an adequate decompression and substantial resolution of the cervical syrinx. C: Image obtained approximately at the 5-year postoperative follow-up, showing an enlarging syrinx and coincident with a return of the patient's preoperative symptoms, underscoring the importance of long-term follow-up in this patient population. 
initiated and not simply worsened by Valsalva maneuvers, and generally of short duration in seconds or minutes) will be relieved and not recur. ${ }^{57}$ The further one drifts away from this strict definition of the Chiari headache, the lower the likelihood of sustained headache and symptom relief.

Syrinx resolution or significant reduction will occur in $80 \%-85 \%$ of patients after initial decompression. With a more aggressive surgical approach to maintain patency of the fourth ventricular outlet in a second procedure (shrinking of one or both cerebellar tonsils with placement of a fourth ventricular-cervical subarachnoid stent), there is near $98 \%$ resolution. ${ }^{57}$ Again, care should be taken not to be complacent in follow-up of this group, as syrinx recurrence may occur years or even decades after initial improvement..$^{3,4,57}$ Scoliosis of less than $40^{\circ}$ will commonly stabilize or improve after decompression, and this is especially true if the patient is younger than 10 years of age at the time of treatment. ${ }^{57,58}$

Infants and young children with cranial nerve deficits and medullary dysfunction have an amazing ability to recover function, even if the pathology is present for many months or years. ${ }^{57}$ Adults with longstanding neurological deficits and dysesthetic pain, however, are not as fortunate. $^{56}$

\section{Conclusions}

Many issues regarding appropriate patient selection and specific techniques to achieve decompression of the craniocervical junction remain; however, progress with our understanding of this clinical entity has truly been impressive. We have given hope and potential resolution to a group of patients previously doomed to a life of disability and discomfort.

\section{Acknowledgments}

We would like to thank Dr. Shane Tubbs for his help in reviewing and editing this manuscript.

\section{References}

1. Adzick NS, Thom EA, Spong CY, Brock JW III, Burrows PK, Johnson MP, et al: A randomized trial of prenatal versus postnatal repair of myelomeningocele. N Engl J Med 364:993-1004, 2011

2. Afshari FT, Wysota B, Oswal M, Mazibrada G, White EA: Emergency foramen magnum decompression for tonsillar herniation secondary to meningoencephalitis. Case Rep Neurol 10:95-100, 2018

3. Aghakhani N, Parker F, David P, Morar S, Lacroix C, Benoudiba F, et al: Long-term follow-up of Chiari-related syringomyelia in adults: analysis of 157 surgically treated cases. Neurosurgery 64:308-315, 2009

4. Alfieri A, Pinna G: Long-term results after posterior fossa decompression in syringomyelia with adult Chiari Type I malformation. J Neurosurg Spine 17:381-387, 2012

5. Armonda RA, Citrin CM, Foley KT, Ellenbogen RG: Quantitative cine-mode magnetic resonance imaging of Chiari I malformations: an analysis of cerebrospinal fluid dynamics. Neurosurgery 35:214-224, 1994

6. Bagley CA, Pindrik JA, Bookland MJ, Camara-Quintana JQ, Carson BS: Cervicomedullary decompression for foramen magnum stenosis in achondroplasia. J Neurosurg 104 (3 Suppl):166-172, 2006
7. Barkovich AJ, Wippold FJ, Sherman JL, Citrin CM: Significance of cerebellar tonsillar position on MR. AJNR Am J Neuroradiol 7:795-799, 1986

8. Battal B, Kocaoglu M, Bulakbasi N, Husmen G, Tuba Sanal $\mathrm{H}$, Tayfun C: Cerebrospinal fluid flow imaging by using phase-contrast MR technique. Br J Radiol 84:758-765, 2011

9. Chern JJ, Gordon AJ, Mortazavi MM, Tubbs RS, Oakes WJ: Pediatric Chiari malformation Type 0: a 12-year institutional experience. J Neurosurg Pediatr 8:1-5, 2011

10. Chiari H: Ueber Veränderungen des Kleinhirns, des Pons und der Medulla oblongata Infolge von congenitaler Hydrocephalie des Grosshirns. Denkschriften Kais Akad Wiss Math-Naturw 63:71-116, 1895

11. Chiari H: Ueber Veränderungen des Kleinhirns infolge von Hydrocephalie des Grosshirns. Dtsch Med Wochenscriff 17:1172-1175, 1891

12. Chumas PD, Armstrong DC, Drake JM, Kulkarni AV, Hoffman HJ, Humphreys RP, et al: Tonsillar herniation: the rule rather than the exception after lumboperitoneal shunting in the pediatric population. J Neurosurg 78:568-573, 1993

13. Cogan DG: Down-beat nystagmus. Arch Ophthalmol 80:757-768, 1968

14. Dobkin BH: The adult Chiari malformation. Bull Los Angeles Neurol Soc 42:23-27, 1977

15. Dyste GN, Menezes AH, VanGilder JC: Symptomatic Chiari malformations. An analysis of presentation, management, and long-term outcome. J Neurosurg 71:159-168, 1989

16. Elster AD, Chen MY: Chiari I malformations: clinical and radiologic reappraisal. Radiology 183:347-353, 1992

17. Elton S, Tubbs RS, Wellons JC III, Blount JP, Grabb PA, Oakes WJ: Acute hydrocephalus following a Chiari I decompression. Pediatr Neurosurg 36:101-104, 2002

18. Fakhri A, Shah MN, Goyal MS: Advanced imaging of Chiari 1 malformations. Neurosurg Clin N Am 26:519-526, 2015

19. Florisson JMG, Barmpalios G, Lequin M, van Veelen MLC, Bannink N, Hayward RD, et al: Venous hypertension in syndromic and complex craniosynostosis: the abnormal anatomy of the jugular foramen and collaterals. J Craniomaxillofac Surg 43:312-318, 2015

20. Freyschmidt J (ed): Borderlands of Normal and Early Pathological Findings in Skeletal Radiography, ed 5. New York: Thieme, 2003

21. Gardner WJ: Hydrodynamic factors in Dandy-Walker and Arnold-Chiari malformations. Childs Brain 3:200-212, 1977

22. Gardner WJ, Abdullah AF, McCormack LJ: The varying expressions of embryonal atresia of the fourth ventricle in adults: Arnold-Chiari malformation, Dandy-Walker syndrome, arachnoid cyst of the cerebellum, and syringomyelia. J Neurosurg 14:591-605, 1957

23. Grabb PA, Mapstone TB, Oakes WJ: Ventral brain stem compression in pediatric and young adult patients with Chiari I malformations. Neurosurgery 44:520-528, 1999

24. Greenlee JDW, Donovan KA, Hasan DM, Menezes AH: Chiari I malformation in the very young child: the spectrum of presentations and experience in 31 children under age 6 years. Pediatrics 110:1212-1219, 2002

25. Hayhurst C, Osman-Farah J, Das K, Mallucci C: Initial management of hydrocephalus associated with Chiari malformation Type I-syringomyelia complex via endoscopic third ventriculostomy: an outcome analysis. J Neurosurg 108:1211-1214, 2008

26. Hofkes SK, Iskandar BJ, Turski PA, Gentry LR, McCue JB, Haughton VM: Differentiation between symptomatic Chiari I malformation and asymptomatic tonsilar ectopia by using cerebrospinal fluid flow imaging: initial estimate of imaging accuracy. Radiology 245:532-540, 2007

27. Isu T, Chono Y, Iwasaki Y, Koyanagi I, Akino M, Abe H, et al: Scoliosis associated with syringomyelia presenting in children. Childs Nerv Syst 8:97-100, 1992 
28. Jansen PR, Dremmen M, van den Berg A, Dekkers IA, Blanken LME, Muetzel RL, et al: Incidental findings on brain imaging in the general pediatric population. $\mathbf{N}$ Engl J Med 377:1593-1595, 2017

29. Kim I, Hopson B, Aban I, Rizk EB, Dias MS, Bowman R, et al: Decompression for Chiari malformation type II in individuals with myelomeningocele in the National Spina Bifida Patient Registry. J Neurosurg Pediatr 22:652-658, 2018

30. Klekamp J: Chiari I malformation with and without basilar invagination: a comparative study. Neurosurg Focus 38(4):E12, 2015

31. Krishna V, Sammartino F, Yee P, Mikulis D, Walker M, Elias $\mathrm{G}$, et al: Diffusion tensor imaging assessment of microstructural brainstem integrity in Chiari malformation Type I. J Neurosurg 125:1112-1119, 2016

32. Langhans T: Über Höhlenbildung im Rückenmark als Folge Blutstauung. Arch Pathol Anat Physiol 85:1-25, 1881

33. Leon TJ, Kuhn EN, Arynchyna AA, Smith BP, Tubbs RS, Johnston JM, et al: Patients with "benign" Chiari I malformations require surgical decompression at a low rate. J Neurosurg Pediatr [epub ahead of print January 4, 2019. DOI: 10.3171/2018.10.PEDS18407]

34. Listernick R, Tomita T: Persistent crying in infancy as a presentation of Chiari type I malformation. J Pediatr 118:567569,1991

35. Loukas M, Noordeh N, Shoja MM, Pugh J, Oakes WJ, Tubbs RS: Hans Chiari (1851-1916). Childs Nerv Syst 24:407-409, 2008

36. Marin-Padilla M, Marin-Padilla TM: Morphogenesis of experimentally induced Arnold-Chiari malformation. J Neurol Sci 50:29-55, 1981

37. Marshman LAG, Benjamin JC, Chawda SJ, David KM: Acute obstructive hydrocephalus associated with infratentorial subdural hygromas complicating Chiari malformation Type I decompression. Report of two cases and literature review. J Neurosurg 103:752-755, 2005

38. Massimi L, Pravatà E, Tamburrini G, Gaudino S, Pettorini B, Novegno F, et al: Endoscopic third ventriculostomy for the management of Chiari I and related hydrocephalus: outcome and pathogenetic implications. Neurosurgery 68:950-956, 2011

39. McGirt MJ, Nimjee SM, Floyd J, Bulsara KR, George TM: Correlation of cerebrospinal fluid flow dynamics and headache in Chiari I malformation. Neurosurgery 56:716-721, 2005

40. McGirt MJ, Nimjee SM, Fuchs HE, George TM: Relationship of cine phase-contrast magnetic resonance imaging with outcome after decompression for Chiari I malformations. Neurosurgery 59:140-146, 2006

41. Merritt HH: A Textbook of Neurology, ed 6. Philadelphia: Lea \& Febiger, 1979

42. Mikulis DJ, Diaz O, Egglin TK, Sanchez R: Variance of the position of the cerebellar tonsils with age: preliminary report. Radiology 183:725-728, 1992

43. Milhorat TH, Chou MW, Trinidad EM, Kula RW, Mandell $\mathrm{M}$, Wolpert C, et al: Chiari I malformation redefined: clinical and radiographic findings for 364 symptomatic patients. Neurosurgery 44:1005-1017, 1999

44. Mortazavi MM, Tubbs RS, Brockerhoff MA, Loukas M, Oakes WJ: The first description of Chiari I malformation with intuitive correlation between tonsillar ectopia and syringomyelia. J Neurosurg Pediatr 7:257-260, 2011

45. Mortazavi MM, Tubbs RS, Hankinson TC, Pugh JA, CohenGadol AA, Oakes WJ: The first posterior fossa decompression for Chiari malformation: the contributions of Cornelis Joachimus van Houweninge Graftdijk and a review of the infancy of "Chiari decompression." Childs Nerv Syst 27:1851-1856, 2011
46. Nagib MG: An approach to symptomatic children (ages 4-14 years) with Chiari type I malformation. Pediatr Neurosurg 21:31-35, 1994

47. Paul KS, Lye RH, Strang FA, Dutton J: Arnold-Chiari malformation. Review of 71 cases. J Neurosurg 58:183-187, 1983

48. Ridder T, Anderson RCE, Hankinson TC: Ventral decompression in Chiari malformation, basilar invagination, and related disorders. Neurosurg Clin N Am 26:571-578, 2015

49. Rocque BG, Oakes WJ: Surgical treatment of Chiari I malformation. Neurosurg Clin N Am 26:527-531, 2015

50. Rozzelle CJ: Clinical presentation of pediatric Chiari I malformations, in Tubbs R, Oakes W (eds): The Chiari Malformations. New York: Springer, 2013, pp 247-251

51. Selmi F, Davies KG, Weeks RD: Type I Chiari deformity presenting with profound sinus bradycardia: case report and literature review. Br J Neurosurg 9:543-545, 1995

52. Shah AH, Dhar A, Elsanafiry MSM, Goel A: Chiari malformation: has the dilemma ended? J Craniovertebr Junction Spine 8:297-304, 2017

53. Stone JJ, Walker CT, Jacobson M, Phillips V, Silberstein HJ: Revision rate of pediatric ventriculoperitoneal shunts after 15 years. J Neurosurg Pediatr 11:15-19, 2013

54. Strahle J, Muraszko KM, Kapurch J, Bapuraj JR, Garton HJL, Maher CO: Chiari malformation Type I and syrinx in children undergoing magnetic resonance imaging. J Neurosurg Pediatr 8:205-213, 2011

55. Strahle J, Muraszko KM, Kapurch J, Bapuraj JR, Garton HJL, Maher CO: Natural history of Chiari malformation Type I following decision for conservative treatment. J Neurosurg Pediatr 8:214-221, 2011

56. Todor DR, Mu HT, Milhorat TH: Pain and syringomyelia: a review. Neurosurg Focus 8(3):E11, 2000

57. Tubbs RS, Beckman J, Naftel RP, Chern JJ, Wellons JC III, Rozzelle CJ, et al: Institutional experience with 500 cases of surgically treated pediatric Chiari malformation Type I. J Neurosurg Pediatr 7:248-256, 2011

58. Tubbs RS, Doyle S, Conklin M, Oakes WJ: Scoliosis in a child with Chiari I malformation and the absence of syringomyelia: case report and a review of the literature. Childs Nerv Syst 22:1351-1354, 2006

59. Tubbs RS, Iskandar BJ, Bartolucci AA, Oakes WJ: A critical analysis of the Chiari 1.5 malformation. J Neurosurg 101 (2 Suppl):179-183, 2004

60. Tubbs RS, Lyerly MJ, Loukas M, Shoja MM, Oakes WJ: The pediatric Chiari I malformation: a review. Childs Nerv Syst 23:1239-1250, 2007

61. Tubbs RS, Oakes WJ: Treatment and management of the Chiari II malformation: an evidence-based review of the literature. Childs Nerv Syst 20:375-381, 2004

62. Tubbs RS, Smyth MD, Wellons JC III, Oakes WJ: Distances from the atlantal segment of the vertebral artery to the midline in children. Pediatr Neurosurg 39:330-334, 2003

63. Tubbs RS, Yan H, Demerdash A, Chern JJ, Fries FN, Oskouian RJ, et al: Sagittal MRI often overestimates the degree of cerebellar tonsillar ectopia: a potential for misdiagnosis of the Chiari I malformation. Childs Nerv Syst 32:1245-1248, 2016

64. van Hoytema GJ, van den Berg R: Embryological studies of the posterior fossa in connection with Arnold-Chiari malformation. Dev Med Child Neurol Suppl 11:61-76, 1966

65. Vernooij MW, Ikram MA, Tanghe HL, Vincent AJPE, Hofman A, Krestin GP, et al: Incidental findings on brain MRI in the general population. N Engl J Med 357:1821-1828, 2007

66. Weig SG, Buckthal PE, Choi SK, Zellem RT: Recurrent syncope as the presenting symptom of Arnold-Chiari malformation. Neurology 41:1673-1674, 1991

67. Williams B: On the pathogenesis of syringomyelia: a review. J R Soc Med 73:798-806, 1980 
68. Williams B: Syringomyelia. Neurosurg Clin N Am 1:653685,1990

69. Wu Y, Li C, Zong X, Wang X, Gui S, Gu C, et al: Application of endoscopic third ventriculostomy for treating hydrocephalus-correlated Chiari type I malformation in a single Chinese neurosurgery centre. Neurosurg $\operatorname{Rev}$ 41:249-254, 2018

\section{Disclosures}

The authors report no conflict of interest concerning the materials or methods used in this study or the findings specified in this paper.

\section{Author Contributions}

Conception and design: both authors. Acquisition of data: both authors. Analysis and interpretation of data: both authors. Drafting the article: both authors. Critically revising the article: both authors. Reviewed submitted version of manuscript: both authors. Approved the final version of the manuscript on behalf of both authors: Oakes.

\section{Correspondence}

W. Jerry Oakes: University of Alabama at Birmingham, Children's Hospital of Alabama, Birmingham, AL. jerry.oakes@ childrensal.org. 